\title{
The embodied view of autism
}

\author{
SZOKOLSZKY ÁGNES ${ }^{1}$ \\ KÉKES SZABÓ MARIETTA ${ }^{2}$
}

\begin{abstract}
In the past decades, research has firmly established that Autism Spectrum Disorder is a multicausal, multilevel phenomenon. With this multidimensional approach, theoretical viewpoints informing empiricalresearch have also become more pluralized. In this paper, we describe a turn towards a meta theoretical shift in cognitive science labeled as "embodiment" and its application to theoriesand research on autism. We show how the premises of the embodied view of cognition: the relational-embodied nature of the mind and the interconnectedness of action, perception, thought, and affect lead to an approach to autism that is different from previous cognitivist approaches. In this framework, we discuss the role of sensorimotor and perception-action processes, as well as intersubjectivity in creating autistic developmental pathways. Autism is understood as rooted in a developmental cascade in which interdependent processes dyna mically influence each other.
\end{abstract}

\section{Keywords}

autistic spectrum disorder, embodied view of autism, sensorimotor development in autism, intersubjectivity in autism, developmental cascade models

\footnotetext{
${ }^{1}$ University of Szeged Faculty of Humanities Institute of Psychology, Department of Cognitive and Neuroscience, E-mail address: szokolszky.agnes@edpsy.u-szeged.hu

${ }^{2}$ University of Szeged Gyula Juhász T eacher Training Faculty, Department of Applied Pedagogy and Psychology,E-mail address: kszmarietta@jgypk.u-szeged.hu
} 